Article

\title{
Red Algae Bloom Detection in Occhito Lake Combining MERIS and MODIS Data
}

\author{
Raffaella Matarrese $^{1, *}$, Nicolas Guyennon ${ }^{1}$, and Diego Copetti ${ }^{1}$ \\ 1 CNR - Water Research Institute - IRSA; guyennon@irsa.cnr.it; copetti@irsa.cnr.it \\ * Correspondence: raffaella.matarrese@ba.irsa.cnr.it; Tel.: +39-080-582-0540
}

\begin{abstract}
In winter 2008-2009, Lake Occhito, a strategic multiple-uses reservoir in South Italy, was affected by an extraordinary Planktothrix rubescens bloom. P. rubescens is a filamentous potentially toxic cyanobacterium which has recently colonized many environments in Europe. A number of studies is currently available on the use of remote sensing techniques to monitor different fresh water cyanobacteria species. By contrast no specific applications are available on the remote sensing monitoring of P. rubescens. In this paper we present a specific algorithm, based on Water Leaving Reflectances (WLR) from MERIS data, atmospherically corrected using the Aerosol Optical Thickness (AOT) retrieved by MODIS data, to detect P. rubescens blooms. The high accuracy in AOT data, provided by MOD09 surface reflectance product, at $1 \mathrm{~km}$ spatial resolution, allowed obtaining a good correlation between the WLR and the P. rubescens chlorophyll-a concentrations measured in the field, through multiple stations fluorometric profiles. A modified Normalized Difference Chlorophyll index (NDCI) algorithm is presented. The performance of the proposed algorithm has been successfully compared with other specific algorithms for turbid productive waters. We demonstrated how important is to verify the spectral behaviour of bio-optical parameters in order to develop an ad hoc algorithm that better performs with respect to standard algorithms.
\end{abstract}

Keywords: P. rubescens algal bloom; remote sensing; MERIS; MODIS

\section{Introduction}

Cyanobacterial blooms are becoming increasingly frequent in lakes [1]. In recent years, the filamentous and potentially toxic cyanobacterium P. rubescens has colonized many environments in Europe [2], often appearing in mesotrophic conditions during the recovery of the trophic state of the lake [3]. A conspicuous presence of this species has been also documented in different lakes located in Northern [4, 5], Central [6, 7] and Southern [8, 9] Italy.

$P$. rubescens is a red-coloured species, also known as 'burgundy blood alga', because its presence can cause an intense redness of the lake water [10,11]. This species can produce microcystins [12, 13], secondary hepatotoxic metabolites suspected to be tumour promoters [9].

In winter 2008-2009 lake Occhito, in Southern Italy, one of the largest Italian and European reservoirs whose water storage is used for both irrigation and drinking supply, was affected by an extraordinary bloom of $P$. rubescens, jeopardizing human health.

It became thus evident, the importance of a constant monitoring of the lake. Local administrations planned a series of measuring campaigns collecting data every month, but only in few points in the whole extent of the lake.

Remote sensing offered the possibility to improve the monitoring and increase the spatial and temporal resolution of the traditional analysis.

In recent years remote sensing techniques are emerging in a wide range of applications both in environmental researches and management issues. Detecting bio-optical parameters in water chlorophyll_a (chl_a) concentration, total suspended sediments and dissolved organic matter), has been one of the first applications of remote sensing techniques, started in 1978 with the launch of NASA's Coastal Zone Color Scanner (CZCS). Since then, many algorithms have been implemented exploiting the spectral behaviour of algal species present in a particular aquatic environment. Some 
algorithms were based on simply band ratio, other, more complex (i.e. semi-analytic or analytic) requiring more ancillary information.

In lacustrine environments much attention has been paid to the monitoring of cyanobacteria blooms [14, 15] because of their potential harmfulness.

Cyanobacteria are generally monitored via remote sensing using the biomarker pigment phycocyanin [16-19]. The latter is a secondary accessory pigment belonging to the family of the phycobiliprotein present in all the cyanobacteria species from which it is used to increase the light harvesting in the visible spectrum [11]. The presence of phycocyanin gives to the reflectance spectrum a specific behaviour. In particular, the presence of absorption feature in reflectances, near $630 \mathrm{~nm}$, and a small peak near $650 \mathrm{~nm}$ have been used to monitor cyanobacteria blooms [20]. For this reason, the most exploited wavelengths to retrieve chlorophyll-a from satellite data are $665 \mathrm{~nm}, 709 \mathrm{~nm}$ and $753 \mathrm{~nm}$.

Gitelson et al. in 2003 [21], proposed an algorithm to retrieve chl_a in higher plants leaves, exploiting reflectances at $665 \mathrm{~nm}, 709 \mathrm{~nm}$, and 753nm. Later, in 2005, Dall'Olmo and Gitelson [22] applied this model (3BDA) and presented its special case (2BDA) for turbid productive waters, using only the first two bands of the 3BDA. In 2011, Bresciani [19], suggested to use a simple band ratio algorithm emphasizing the reflectance peak between $620 \mathrm{~nm}$ and $560 \mathrm{~nm}$, obtaining good results in the retrieval of cyanobacteria blooms. Mishra and Mishra [23], in 2012, based on the Normalized Difference Vegetation Index (NDVI) proposed the Normalized Difference Chlorophyll Index (NDCI) to predict chl_a concentration from MERIS images in estuarine and coastal turbid productive waters, centred in the same two bands of 2BDA.

In addition to phycocyanin, $P$. rubescens cells contain phycoerythrin the secondary pigment (phycobiliprotein) responsible for the intense red colour of its blooms [24]. Compared to phycocyanin a minor number of remote sensing studies addressed their attention to phycoerythrin. Most of these studies considers the portion of the spectrum affected by phycoerythrin only to get a better estimate of phycocyanin $[25,26]$, and in particular only one specific application is available for the monitoring of $P$. rubescens [27].

It is well known from literature [28] that this pigment presents a shifted absorption peak with respect to phycocyanin behaviour, as shown in Figure 1. The consequence is a stronger signal in reflectance between $709 \mathrm{~nm}$ and $680 \mathrm{~nm}$.



Figure 1: Comparison of the absorption behaviour of phycoerythrin and phycocyanin pigments.

In this paper we suggest to use signal at $680 \mathrm{~nm}$ to better discriminate phycoerythrin and thus $P$. rubescens chl_a concentration. We present a modified NDCI algorithm based on Water Leaving 
Reflectances (WLR) from MERIS data, atmospherically corrected using the Aerosol Optical Thickness (AOT) retrieved by MODIS data, to detect $P$. rubescens blooms exploiting the peculiar characteristics of this specie of algae [27]. In particular band $8(681 \mathrm{~nm})$ and band $9(709 \mathrm{~nm})$ have been used. The model was tested using multiple station chlorophyll-a profiles of $P$. rubescens conducted on Lake Occhito during a very strong bloom of this species. Results were statistically analysed and compared with the most efficient algorithm found in literature to retrieve cyanobacteria.

\section{Materials and Methods}

\subsection{Study area}

With maximum surface area and total usable volume of around $14 \mathrm{~km}^{2}$ and $24710^{6} \mathrm{~m}^{3}$ respectively, Lake Occhito is one of the largest Italian and European reservoirs (Table 1).

Table 1. Morphometric features of Lake Occhito

\begin{tabular}{lll}
\hline Variable & Value & Unit \\
\hline Watershed area & 1,012 & $\mathrm{~km}^{2}$ \\
Lake area & 13.74 & $\mathrm{~km}^{2}$ \\
Maximum elevation & 198 & $\mathrm{~m}$ a.s.l. \\
Maximum depth & 40 & $\mathrm{~m}$ \\
Lake volume & $33310^{6}$ & $\mathrm{~m}^{3}$ \\
Irrigation network area & 600 & $\mathrm{~km}^{2}$ \\
\hline
\end{tabular}

The dam was built at the end of 1950' on the bed of the Fortore River at the border between the Puglia and the Molise Regions (Figure 2).

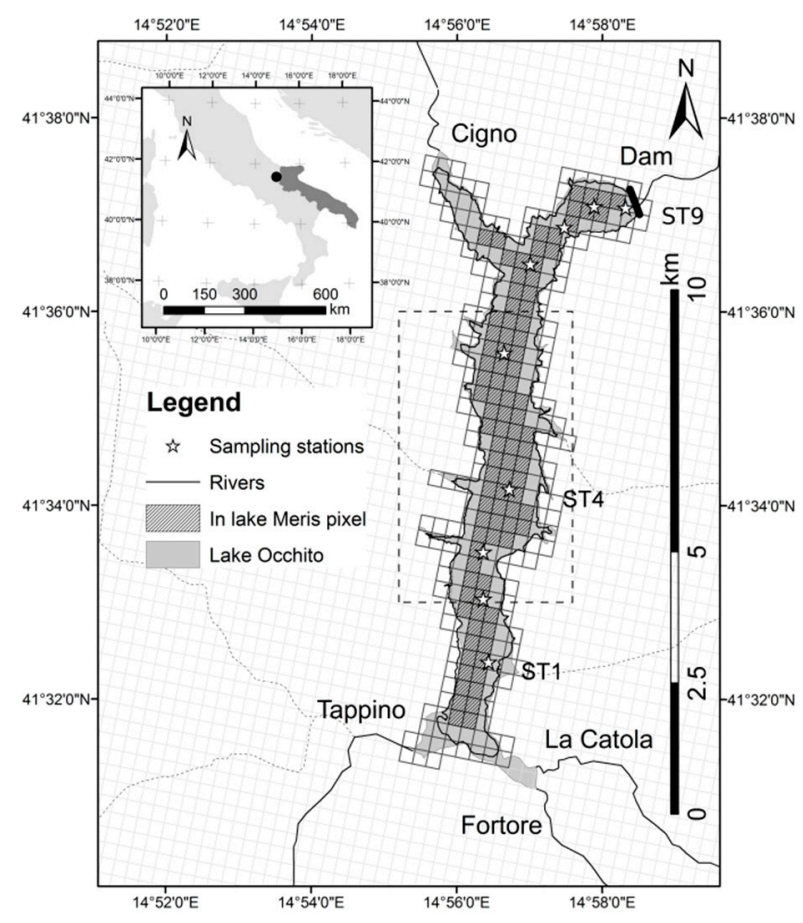

Figure 2: Position of the study area (upper left panel) and details of the Lake Occhito on the $6^{\text {th }}$ of April 2009 sampling date. Grey surface: maximum lake area (195 m a.s.l.); black full line: lake shore line during the sampling; dotted line permanent inflows and outflows; stars: fluorometric sampling stations. Overlaid to the figure is represented the MERIS grid. Filled grey cells: water pixels, empty cells: land-water pixels (not used). The dashed rectangle delimits the area where the AOT by MOD09 were averaged over the lake surface (see text for details). 
The watershed of the reservoir $\left(\approx 1000 \mathrm{~km}^{2}\right)$ drains the waters of a number of temporary streams and of four permanent inflows (Figure 2). Total inflow to the lake is around $7 \mathrm{~m}^{3} \mathrm{~s}^{-1}$. The reservoir has a theoretical water renewal time of about 1 year. Lake Occhito is a strategic reservoir whose water storage is used for both irrigation and drinking supply. In particular it is the only source of drinking water for the entire Province of Foggia (around $70010^{3}$ inhabitants) and the principal irrigational source of water for the "Tavoliere di Puglia", one of the most productive agricultural area in South Italy. The reservoir is subjected to a level oscillation of about $7 \mathrm{~m}$ between the filling (November-March) and the emptying phase (April-October). At the end of the filling phase the reservoir can reach a maximum level of $195 \mathrm{~m}$ a.s.l. at which corresponds a maximum depth of around $40 \mathrm{~m}$ at the base of the dam (Figure 2). Here the lake waters are withdrawn at a fixed height $(\approx 28 \mathrm{~m})$ above the lake bottom. After withdrawal the water runs by gravity into a dark tunnel for about $16 \mathrm{~km}$ and then it is stored in a superficial splitter (Finocchito) where it is distributed to the drinking treatment plant and to the irrigation network (total served area $>1000 \mathrm{~km}^{2}$ ) respectively.

The presence of $P$. rubescens in Lake Occhito was detected for the first time during the winter 2008-2009 when an extraordinary bloom of this species was observed [29]. The bloom development followed a typical trend already described in other Italian lakes (eg [30, 31]) with a marked winter-spring peak followed by a decrease of the P. rubescens population in summer. P. rubescens cell density was around $4010^{6} \mathrm{cell} \mathrm{l}^{-1}$ in February and reached a maximum of about $16010^{6} \mathrm{cell} \mathrm{l}^{-1}$ in march [24]. The P. rubescens density then remained high throughout the month of March and at the beginning of April 2009. Subsequently the P. rubescens density abruptly decreased to values of 20-40 $10^{6}$ cell $1^{-1}$ until July 2009. Up to July 2009 the phytoplankton population was markedly dominated by P. rubescens. In particular in April 2009 about $90 \%$ of the phytoplankton biomass was due to this species [12, 29].

\subsection{Field data}

Several field campaigns were conducted in the present study from October 2008 to January 2011. In particular in April 2009 Chlorophyll-a concentration profiles were performed in 9 lake sampling stations (stars in Fig. 1) using the portable fluorometer bbe Moldanke FluoroProbe (http://www.bbe-moldaenke.de/), able to differentiate the chlorophyll-a content associated to four algal spectral classes, using class-specific fluorometric fingerprints [32]. The $P$. rubescens fingerprint used in this study in particular was previously determined [4] using natural strains of this species from Lake Pusiano (North Italy).

P. rubescens chlorophyll-a data were averaged over the first $5 \mathrm{~m}$ of the water column before the comparison with satellite data.

\subsection{Satellite data}

Satellite imagery used in this study were MERIS (Medium Resolution Imaging Spectrometer, data provided by (C ESA (2016)) and MODIS (Moderate Resolution Imaging Spectrometer) sensors.

MERIS (http://envisat.esa.int/handbooks/meris/) is a $68.5^{\circ}$ field-of-view pushbroom imaging spectrometer that measures the solar radiation reflected by the Earth at a ground spatial resolution of $300 \mathrm{~m}$ in 15 programmable spectral bands between 390 and $1040 \mathrm{~nm}$. Its primary objective is to enable quantitative observations of marine constituents such as chlorophyll-a, total suspended solid, dissolved organic matter, etc. [32]. The spatial and spectral resolutions provided by this sensor are the most suitable for the study presented in this paper. MERIS data provides a global coverage every 3 days.

MODIS (http://modis.gsfc.nasa.gov/) is a key instrument aboard the TERRA (EOS AM) and AQUA (EOS PM) satellites. TERRA's orbit around the Earth is timed so that it passes from north to south across the equator in the morning, while AQUA passes from south to north over the equator in the afternoon. This allows TERRA and AQUA MODIS to view the entire Earth's surface every 1 or 2 days, acquiring data in 36 spectral bands, or groups of wavelengths, with $1 \mathrm{~km} \times 1 \mathrm{~km}$ of spatial resolution. 
The requirement to collect MERIS; MODIS and in situ measurements at the same time, led to a total of 16 images to analyse, and a total of 33 pixels corresponding to in situ stations. Consequently, 16 MERIS images and corresponding MODIS surface reflectance product (MOD09) related to the study area, were acquired and used to calibrate and validate the linear regression model between satellite reflectances and $P$. Rubescens chlorophyll-a concentrations measured in the field.

In addition to the surface reflectance, the MOD09 product provided the AOT distribution (at 1 $\mathrm{km}$ spatial resolution) of the target area. The AOT at $555 \mathrm{~nm}$ computed by MOD09 was averaged over the lake surface as showed in Figure 2 (dashed rectangle) and then used to atmospherically correct MERIS data using SMAC processor (http://www.brockmann-consult.de/cms/web/beam/) of VISAT-BEAM.

SMAC is a Simplified Method for Atmospheric Corrections of satellite measurements. It is a semi-empirical approximation of the radiative transfer in the atmosphere, that considers two way gaseous transmission, atmospheric spherical albedo, total atmospheric transmission, Rayleigh scattering and aerosol scattering [33].

\section{Results}

\subsection{Band math approach to detect P. rubescens}

Figure 3 shows 9 examples of spectral signatures (extracted from MERIS data) corresponding to the 9 stations sampled on the $6^{\text {th }}$ of April 2009 on Lake Occhito, before (Figure 3a) and after (Figure 3b) the atmospheric correction.
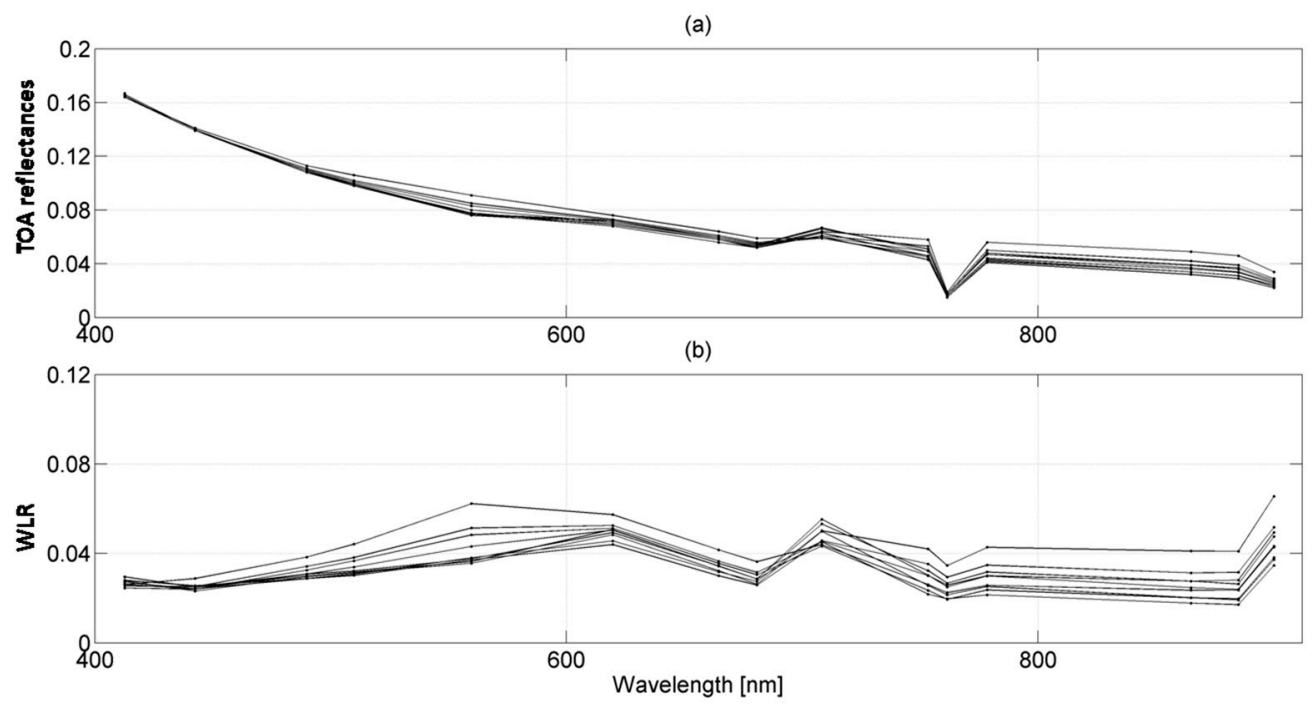

Figure 3: Spectral signatures corresponding to 9 sampling stations on April $6^{\text {th }}$, 2009, before and after the atmospheric correction. a) TOA=Top Of Atmosphere Reflectances; b) WLR=Water Leaving Reflectances.

From Figure 3 it can be noticed the strong effect of the atmosphere on the MERIS signal. The atmospheric correction in particular reveals 2 marked peaks in Band 5 (560nm) and Band 9 (709 nm) of the MERIS WLR, coherent to the spectral signature measured from [27].

In contrast with literature algorithms, the presented approach, exploits the red peak in the $P$. rubescens spectrum, and with a normalized band ratio algorithm, amplifies the gap between Band 9 (708nm) and Band 8 (681nm) of MERIS data, as described in the following equation:

$$
\mathrm{WLR}_{\text {ratio }}=(\mathrm{B} 9-\mathrm{B} 8) /(\mathrm{B} 9+\mathrm{B} 8) \text {, }
$$

\subsection{Data analysis and comparison with different algorithms to detect Chlorophyll_a concentration}

According to [34], the most used remote sensing models based on bio-optical parameters to detect chl_a concentration from MERIS data are those reported in Table 2. 
Table 2: Summary of the most used chl_a concentration detection models. (B\# refers to the band number of MERIS)

\begin{tabular}{cc}
\hline Name & Algorithm \\
\hline 2BDA & chl_a $\approx \mathrm{B} 9 / \mathrm{B} 7$ \\
3BDA & chl_a $\approx\left(\mathrm{B} 7^{-1}-\mathrm{B} 9-1\right)^{*} \mathrm{~B} 10$ \\
NCDI & chl_a $\approx(\mathrm{B} 9-\mathrm{B} 7) /(\mathrm{B} 9+\mathrm{B} 7)$ \\
Bresciani & chl_a $\approx \mathrm{B} 6 / \mathrm{B} 5$ \\
\hline
\end{tabular}

The first three algorithms have been developed for generic algae signatures, while Bresciani algorithm is specific to detect chl_a concentration from cyanobacteria.

From a preliminary analysis, the best correlations between model and measures of chl_a concentration are highlighted by using the 4 th algorithm in the table. Therefore, a robust statistical analysis was conducted to compare the applicability of the Bresciani model and the proposed model (WLR ratio) in eq. (1).

The analysis has been focused on three variables, namely the observed Chl_a data, the WLR ratio and Bresciani variables. Since the declared objective is to provide a model for predicting the Chl_a data from WLRratio or Bresciani datasets, the normality of all the three datasets has been checked before the application of the regression model. Table 3 accounts for the summary statistics of the three analysed variables:

Table 3: Table reporting the summary statistics related to the three analysed variables.

\begin{tabular}{cccc}
\hline Summary Statistics & Chl_a & Bresciani & WLR ratio \\
\hline \# Observations & 20 & 20 & 20 \\
Minimum & 1.300 & 0.456 & -0.179 \\
Maximum & 29.605 & 1.623 & 0.415 \\
$1^{\circ}$ Quartile & 3.175 & 0.645 & -0.028 \\
Median & 9.799 & 0.789 & 0.109 \\
$3^{\circ}$ Quartile & 20.576 & 1.151 & 0.325 \\
Median & 11.387 & 0.932 & 0.130 \\
Standard Deviation (n-1) & 9.176 & 0.380 & 0.204 \\
Coefficient variation & 0.785 & 0.398 & 1.530 \\
Asymmetry (Pearson) & 0.565 & 0.687 & 0.108 \\
Kurtosis (Pearson) & -1.036 & -0.905 & -1.407 \\
\hline
\end{tabular}

Currently, different statistical tests are available for checking the normality of a given dataset. In this study, four different tests have been applied, namely Shapiro-Wilk, Anderson-Darling, Lilliefors and Jarque-Bera $[35,36]$. Most of the tests indicated the non-linearity of the datasets. Therefore, before modelling both dependent (Chl_a) and independent variables (WLRratio and Bresciani datasets) were transformed in order to meet the main assumptions underlying the linear regression model. This has been achieved through a Box-Cox transform [37] whose explicit equation is provided below:

$$
Z_{i}=\left\{\begin{array}{c}
Y_{i}^{\lambda}, \lambda \neq 0 \\
\log Y_{i}, \lambda=0
\end{array}\right.
$$


In particular, the WLR ratio dataset underwent to a log transform, while Chl_a and Bresciani were subjected to a $\lambda$-transform. A test check downstream after the transform, confirmed that all the three datasets are now Gaussian and linear. Therefore, hereafter we refer to the transformed variables as $\mathrm{BC}\left(\mathrm{Chl} \_\mathrm{a}\right), \mathrm{BC}($ WLRratio $)$ and BC(Bresciani). An evaluation of the linear correlation between $\mathrm{BC}\left(\mathrm{Chl} \_\mathrm{a}\right), \mathrm{BC}\left(\mathrm{WLR}_{\text {ratio}}\right)$, and $\mathrm{BC}($ Bresciani) is suitable before modelling to check for a relationship between the dependent variables and the independent ones. The values of the Pearson correlation coefficient are about 0.97 and 0.91 respectively for the couples $\mathrm{BC}\left(\mathrm{Chl} \_\mathrm{a}\right)$ - BC(WLRratio), and BC(Chl_a) - BC(Bresciani). Table 4 accounts for the summary statistics of the Box-Cox transformed variables. It is quite evident the similarity between mean and median and the reduced value of asymmetry after the transform, which proves the success of the transform.

Table 4: Table reporting the summary statistics related to the three analysed variables after Box-Cox transform.

\begin{tabular}{cccc}
\hline Summary Statistics & BC(Chl_a) & BC(Bresciani) & BC(WLR ratio) \\
\hline \# Observations & 20 & 20 & 20 \\
Minimum & 0.270 & -0.931 & -0.198 \\
Maximum & 5.025 & 0.438 & 0.347 \\
$1^{\circ}$ Quartile & 1.306 & -0.483 & -0.029 \\
Median & 2.961 & -0.251 & 0.103 \\
$3^{\circ}$ Quartile & 4.290 & 0.135 & 0.281 \\
Median & 2.704 & -0.183 & 0.106 \\
Standard Deviation (n-1) & 1.570 & 0.415 & 0.182 \\
Coefficient variation & 0.566 & -2.205 & 1.668 \\
Asymmetry (Pearson) & -0.102 & 0.061 & -0.057 \\
Kurtosis (Pearson) & -1.366 & -1.070 & -1.344 \\
\hline
\end{tabular}

\section{Discussion}

Two univariate regression analyses have been carried out by coupling BC(Chl_a) - BC(WLRratio) and BC(Chl_a) - BC(Bresciani), and the respective results have been compared in order to ascertain what is the best predictor of the BC(Chl_a). A number of statistical indices have been computed for assessing the best prediction accuracy between the two regression models.

The equation of the first linear model analyzed is:

$$
\text { BC }(\text { Chl_a })=1.81830+8.31542 * B C(\text { WLRratio })
$$

The F test carried out to assess the significance of the linear model produced a $p$-value less than 0.0001 , then highly significant. Two t-tests have been performed to assess the significance of the slope and the intercept of the model. Once more, the tests produced two p-values very significant (less than 0.0001). Finally, $\mathrm{R}^{2}$, the goodness-of-fit coefficient, showed a value of 0.932 .

The second equation is:

$$
\text { BC } \left.(\text { Chl_a })=3.33915+3.46863^{*} \text { BC (Bresciani }\right)
$$

The values of the statistics $F$ and $t$ are very significant as for the previous equation, while $R^{2}$ assumes a value smaller with respect the previous model $(0.839)$. This preliminary comparison seems to indicate the first equation as the best predictor. The following accuracy statistics have been computed [38]:

the Mean Absolute Error (MAE): 
the Root Mean Square Error (RMSE)

$$
M A E=\frac{\sum_{i=1}^{n}\left|r_{i}\right|}{n}
$$

$$
R M S E=\sqrt{\frac{\sum_{i=1}^{n}\left(r_{i}\right)^{2}}{n}}
$$

the Relative MAE (RMAE) has the same meaning as the MAE but is rescaled in terms of the corresponding observed value

$$
R M A E=\frac{1}{n} \sum_{i=1}^{n} \frac{\left|r_{i}\right|}{z\left(x_{i}\right)}=\frac{1}{n} \sum_{i=1}^{n} \frac{r_{i}^{a}}{z\left(x_{i}\right)}
$$

where

$$
r_{i}=z\left(x_{i}\right)-z^{*}\left(x_{i}\right)
$$$$
i=1, \ldots, n
$$

are the residuals obtained as difference between the observed minus the predicted value.

In summary, the computed statistics are showed in Table 5.

Table 5: Accuracy assessment of the two proposed linear models.

\begin{tabular}{lll}
\hline Statistics & WLR ratio & Bresciani \\
\hline MAE & 1.70 & 2.60 \\
RMSE & 2.16 & 3.40 \\
RMAE & 0.21 & 0.37 \\
\hline
\end{tabular}

As emerges from the above reported results, the BC(WLRratio) outperforms by far the $\mathrm{BC}($ Bresciani) model. In particular, the most remarkable value is RMAE, which says that BC(WLRratio) produces a relative prediction error of about the $21 \%$, on average; while BC(Bresciani) produces a relative prediction error of about $37 \%$, on average.

\section{Conclusions}

By exploiting the spectral characteristics of the toxic algae $P$. rubescens, which exhibits an accentuated red color in the colonizing waters, a specific algorithm for determination of chl_a concentration derived from this species was investigated.

The combined use of MERIS and MODIS images has allowed significant correlation between the index created in this study and the chlorophyll measured in situ on the study area of Lake Occhito. Only through an accurate atmospheric correction, carried out with the SMAC processor of the VISAT-Beam software, it was possible to disclose the specific spectrum characteristic of $P$. rubescens [27].

Unlike the spectra associated with the most common cianobacteria, P. rubescens shows a peak in red (around $700 \mathrm{~nm}$ ) due to the most important presence in these algal species of the secondary pigment of phycoerythrin rather than phycocyanin [20].

A robust statistical analysis of the data set available by comparing the algorithm proposed in this study with those most used in the literature, shows the best reliability of the proposed index, demonstrating how important is to verify the spectral behavior of bio-optical parameters in order to develop an ad hoc algorithm that better performs with respect to standard models.

The reliability of the results presented in this study on the quantification of the $P$. rubescens biomass opens important perspectives for the monitoring of this potentially toxic species via remote sensing. The specificity of the spectrum associated to P. rubescens allows indeed differentiating this species from others.

Remote sensing techniques appear thus as a very useful tool to monitor the current spread of this species over the European countries. Remote sensing applications in the early detection (early warning) of this species in strategic multiple uses reservoirs as well as intensive investigation of bloom formation and evolution are also expected in the near future. 
Acknowledgments: The authors wish to thank the Consorzio per la Bonifica della Capitanata (Foggia) the management authority of the Lake Occhito dam for supporting the field campaign conducted in this study.

Author Contributions: Raffaella Matarrese managed remote sensing images, from the atmospheric corrections to the creation of the algorithm. Nicolas Guyennon contributed to the data analysis and the image processing. Diego Copetti supervised the research activities and verified the bio-physical coherence of data. The manuscript was written by the first author, which integrated specific contributions from the other two co-authors.

Conflicts of Interest: The authors declare no conflict of interest.

\section{References}

1. Paerl, W.; Huisman, J. Climate change: a catalyst for global expansion of harmful cyanobacterial blooms. Environmental Microbiology Reports 2009, 1(1), 27-37.

2. Ernst, B.; Hoeger, S.J.; O'Breien, E.; Dietrich, D. R. Abundance and toxicity of Planktothrix rubescens in the pre-alipine Lake Ammersee. Harmful Algae 2009, 8, 329-342.

3. Copetti, D.; Salerno, F.; Valsecchi, L.; Viviano, G.; Buzzi, F.; Agostinelli, C.; Formenti, R.; Marieri, A. and Tartari, G. (2017). Restoring lakes through external phosphorus load reduction: the case of Lake Pusiano (Southern Alps). Inland Waters 7(1), 100-8.

4. Carraro, E.; Guyennon, N.; Hamilton, D.; Valsecchi, L.; Manfredi, E.; Viviano, G.; Salerno, F.; Tartari, G.; Copetti, D. Coupling high-resolution measurements to a three-dimensional lake model to assess the spatial and temporal dynamics of the cyanobacterium Planktothrix rubescens in a medium-sized lake. Hydrobiologia 2012, 698(1), 77-95.

5. Salmaso, N. Factors affecting the seasonality and distribution of cyanobacteria and chlorophytes: A case study from the large lakes south of the Alps, with special reference to Lake Garda. Hydrobiologia 2000, 438, 43-63.

6. Messineo, V.; Mattei, D.; Melchiorre, S.; Salvatore, G.; Bogialli, S.; Salzano, R.; Mazza, R.; Capelli, G.; Bruno, M. Microcystin diversity in a Planktothrix rubescens population from Lake Albano (Central Italy). Toxicon 2006, 48(2), 160-174.

7. Manganelli, M.; Scardala, S.; Stefanelli, M.; Vichi, S.; Mattei, D.; Bogialli, S.; Ceccarelli, P.; Corradetti, E.; Petrucci, I.; Gemma, S.; Testai, E.; Funari, E. Health risk evaluation associated to Planktothrix rubescens: An integrated approach to design tailored monitoring programs for human exposure to cyanotoxins. Water Res. 2010, 44(5), 1297-1306.

8. Naselli-Flores, L.; Barone, R.; Chorus, I.; Kurmayer, R. Toxic cyanobacterial blooms in reservoirs under a semiarid Mediterranean climate: The magnification of a problem. Environmental Toxicology 2007, 22(4), 399-404.

9. Bogialli, S.; Nigro di Gregorio, F.; Lucentini, L.; Ferretti, E.; Ottaviani, M.; Ungaro, N.; Abis, P.P.; Cannarozzi de Grazia, M. Management of a Toxic Cyanobacterium Bloom (Planktothrix rubescens) Affecting an Italian Drinking Water Basin: A Case Study. Environmental Science \& Technology 2012, 47(1), 574-583.

10. Walsby, A.E.; Schanz, F.; Schmid, M. The Burgundy-blood phenomenon: A model of buoyancy change explains autumnal waterblooms by Planktothrix rubescens in Lake Zürich. New Phytologist 2006, 169(1), 109-122.

11. Reynolds, C.S. The ecology of phytoplankton. First ed., Cambridge University Press, Cambridge, New York, Melburne, Madrid, Cape Town, Singapore, São Paolo, 2006.

12. Salmaso, N.; Copetti, D.; Cerasino, L. ; Shams, S.; Capelli, C.; Boscaini, A.; Valsecchi, L.; Pozzoni, F.; Guzzella, L. Variability of microcystin cell quota in metapopulations of Planktothrix rubescens: Causes and implications for water management. Toxicon 2014, 90(0), 82-96.

13. Haruštiaková, D. and Welker, M. Chemotype diversity in Planktothrix rubescens (cyanobacteria) populations is correlated to lake depth. Environmental Microbiology Reports 2017, 9(2), 158-68.

14. Bresciani, M.; Giardino, C.; Lauceri, R.; Matta, E.; Cazzaniga, I.; Pinardi, M.; ... Morabito, G. Earth observation for monitoring and mapping of cyanobacteria blooms. Case studies on five Italian lakes. Journal of Limnology, 2016, 18. https://doi.org/10.4081/jlimnol.2016. 
15. Zhang, M.; Zhang, Y.; Yang, Z.; Wei, L.; Yang, W.; Chen, C.; and Kong, F. Spatial and seasonal shifts in bloom-forming cyanobacteria in Lake Chaohu: Patterns and driving factors. Phycological Research, 2016, 64(1), 44-55. https://doi.org/10.1111/pre.12112

16. Kutser, T. Quantitative detection of chlorophyll in cyanobacterial blooms by satellite remote sensing. Limnology and Oceanography 2004, 49(6), 2179-2189.

17. Simis, S.G.H.; Peters, S.W.M.; Gons, H.J. Remote sensing of the cyanobacterial pigment phycocyanin in turbid inland water. Limnology and Oceanography 2005, 50(1), 237-245.

18. Hunter, P.D.; Tyler, A.N.; Willby, N.J.; Gilvear, D.J. The spatial dynamics of vertical migration by Microcystis aeruginosa in a eutrophic shallow lake: A case study using high spatial resolution time-series airborne remote sensing. Limnology and Oceanography 2008, 53(6), 2391-2406.

19. Bresciani, M.; Giardino, C.; Bartoli, M.; Tavernini, S.; Bolpagni, R.; Nizzoli, D. Recognizing harmful algal bloom based on remote sensing reflectance band ratio. APPRES 2011, 5(1), 053556-053556.

20. Kutser, T.; Metsamaa, L.; Strömbeck, N.; Vahtmäe, E. Monitoring cyanobacterial blooms by satellite remote sensing. Estuarine, Coastal and Shelf Science 2006, 67(1-2), 303-312.

21. Gitelson, A.A.; Gritz, U.; Merzlyak, M.N. Relationships between leaf chlorophyll content and spectral reflectance and algorithms for non-destructive chlorophyll assessment in higher plant leaves. J. Plant Physiol. 2003, 160, 271-282.

22. Dall'Olmo, G.; Gitelson, A.A. Effect of bio-optical parameter variability on the remote estimation of chlorophyll-a concentration in turbid productive waters: Experimental results. Appl. Opt. 2005, 44, 412-422.

23. Mishra, S.; Mishra, D.R. Normalized difference chlorophyll index: A novel model for remote estimation of chlorophyll-a concentration in turbid productive waters. Remote Sens. Environ. 2012, 117, 394-406.

24. Beutler, M.; Wiltshire, K.H.; Reineke, C.;Hansen, U.P. Algorithms and practical fluorescence models of the photosynthetic apparatus of red cyanobacteria and Cryptophyta designed for the fluorescence detection of red cyanobacteria and cryptophytes. Aquatic Microbial Ecology 2004, 35(2), 115-129.

25. Kolokolova, L.; Sparks, W.; Mackowski, D. Astrobiological remote sensing with circular polarization. In Polarimetric Detection, Characterization and Remote Sensing; Mishchenko, Yatskiv, Rosenbush, Videen, Eds., Springer Netherlands, 2011, pp. 277-294.

26. Bernard, S.; Pitcher, G.; Evers-King, H.; Robertson, L.; Matthews, M.; Rabagliati, A.; Balt, C. Ocean Colour Remote Sensing of Harmful Algal Blooms in the Benguela System. Remote Sensing of the African Seas, Barale; Gade, Eds, Springer Netherlands, 2014, pp. 185-203.

27. Maltese, A.; Capodici, F.; Ciraolo, G.; Loggia, G.L.; Granata, A.; Corbari, C. Planktothrix rubescens in freshwater reservoirs: Remote sensing potentiality for mapping cell density. Proceedings of SPIE, Edinburgh, United Kingdom, 24-27 September 2012.

28. Photosynthesis Lab Manual. York University, 2013.

URL: http://biologywiki.apps01.yorku.ca/images/e/e9/Pigment_spectra.png.

29. Assennato, G.; Blonda, M.; Cudillo, B.; Gifuni, S.; Petruzzelli, M.R.; Pastorelli, A.M.; Ungaro, N. Cyanobacteria bloom in the occhito artificial lake (southern Italy): Relationship between planktothrix rubescens density and microcystin concentration. Fresenius Environmental Bulletin 2010, 19(9), 1795-1801.

30. Salmaso, N.; Boscaini, A.; Shams, S.; Cerasino, L. Strict coupling between the development of Planktothrix rubescens and microcystin content in two nearby lakes south of the Alps (lakes Garda and Ledro). Annales de Limnologie - International Journal of Limnology 2013, 49(04), 309-318.

31. Legnani, E.; Copetti, D.; Ogioni, A.; Tartari, G.; Palumbo, M.T.; Morabito, G. Planktothrix rubescens' seasonal dynamics and vertical distribution in Lake Pusiano (North Italy). Journal of limnology 2005, 64(1), 61-73.

32. Rast, M.; Bezy, J.L.; Bruzzi, S. The ESA Medium Resolution Imaging Spectrometer MERIS a review of the instrument and its mission. International Journal of Remote Sensing 1999, 20(9), 1681-1702.

33. Rahaman, H.; Dedieu G. SMAC: a simplified method for the atmospheric correction of satellite measurements in the solar spectrum. Int. J. Remote Sensing 1994, 15(1), 123-143.

34. Augusto-Silva, P.B.; Ogashawara, I.; Barbosa, C.C.F.; de Carvalho, L.A.S.; Jorge, D.S.F.; Fornari, C.I.; Stech, J.L. Analysis of MERIS reflectance algorithms for estimating chlorophyll-a concentration in a Brazilian Reservoir. Remote Sensing 2014, 6, 11689-117077

35. Razali, N.; Wah, Y.B. Power comparisons of Shapiro-Wilk, Kolmogorov-Smirnov, Lilliefors and AndersonDarling tests. Journal of Statistical Modeling and Analytics 2011, 2 (1), 21-33. 
36. Jarque, C.M.; Bera, A.K. Efficient tests for normality, homoscedasticity and serial independence of regression residuals: Monte Carlo evidence. Economics Letters 1981, 7(4), 313-318.

37. Li, F. Box-Cox Transformations: An Overview, Sao Paulo, Brazil: University of Sao Paulo, Brazil, 2005.

38. Willmott, C.J.; Matsuura, K.; Robeson, S.M. Ambiguities inherent in sums-of-squares-based error statistics Atmos. Environ. 2009, 43, 749-752. 